\title{
Effect of Mortise and Tenon Size on Compressive and Tensile Strength of a Box Connected by Dovetail Keys
}

\author{
Shuo Wang, ${ }^{\mathrm{a}}$ Zhi Hui Wu, ${ }^{\mathrm{b}, *}$ Lu Chen, ${ }^{\mathrm{a}}$ Sheng Zan Yan, ${ }^{\mathrm{a}}$ LiJun Xu, ${ }^{\mathrm{a}}$ and Hao Guan, ${ }^{\mathrm{a}}$ \\ Compressive and tensile strengths were considered for a box connected \\ by dovetail keys under different mortise-and-tenon sizes. Poplar wood \\ modified by melamine resin (MF modified poplar wood) was chosen as the \\ experimental material, and the experimental study was carried out on the \\ box using the concentrated loading method. The results showed that the \\ ratio $(T)$ of hole depth to slope height had a significant effect on the \\ structural strength of the box connected by dovetail keys when other \\ dimensional parameters were the same. When $T$ was equal to $75 \%$, the \\ compression and tensile strength of the box was the highest, and the joint \\ had better recovery and deformation ability. When $T$ ' was equal to $50 \%$, \\ the box strength was the worst, and the joint damage was the most serious \\ in both types of loading. In addition, the measurement standard of the \\ displacement was determined through preliminary experimentation. The \\ compression quantity was $8 \mathrm{~mm}$, and the stretching quantity was $5 \mathrm{~mm}$. \\ The latter experiment showed the reliability of the pre-experiment.
}

Keywords: Mortise-and-tenon size; Dovetail key; Compressive; Tensile

Contact information: a: Department of Industrial Design, Nanjing Institute of Technology, 211167, Nanjing, China; b: Department of Furniture Design, Nanjing Forestry University, 210037 Nanjing, China;

* Corresponding author: wzh550@sina.com

\section{INTRODUCTION}

Dovetail is the main type of contact joint employed in box-type furniture. Such joints provide higher contact force and anti-deformation capacity than other mortise-andtenon joints (Li et al. 2011; Wang et al. 2015). There are many studies on dovetail tenons including the fit size of tenons (Yang et al. 2017), the failure mode (Wang 2016; Zhang et al. 2019), and materials (Li and Yang 2011). However, most research has been based on Ishaped and L-shaped components, without considering the overall mechanical properties of the box structure in practical applications. Moreover, they have ignored the research on the miter spline structure.

Yang (2017) established a parametric finite element model of the dovetail tenon structure by ANSYS. Yang (2017) also obtained the fit size of the mortise and tenon when the tensile force was maximized by the optimization analysis. When the angle between the dovetail mortise and the dovetail surface as well as the interference fit amount remained unchanged, the dovetail mortise thickness factor was greater. This also resulted in greater maximum tensile force in the dovetail mortise.

Zhang (2019) found that the stress at the tenon of each component of the dovetail structure was relatively high, especially at the root of the v-shaped tenon. Therefore, the tenon easily produced a yield failure under pressure, which was obtained from the finite element analysis of the L-shaped components. At the same time, the material stress of the dovetail in the direction of tension increased. Zhang et al. (2019) proposed that when designing and manufacturing dovetails, the material in the longitudinal direction where the 
wood is more subjected to tensile stress should be used as the material in the direction of the stretched component.

Li and Yang (2011) analyzed the material characteristics of paulownia and the boxtype structure of paulownia furniture. The study also involved testing the stability, strength, and bonding force between the traditional structure and the improved structure. Li and Yang (2011) proposed that the cross-grain tensile strength of the detachable structure (using glue-free dovetail) was related to the inclination of the bevel part of the tenon. Additionally, the compressive strength of the tenon material and its tensile strength mainly depended on the friction and pressure generated by the mortise and tenon joint.

Strength of the mortise and tenon joints was determined by the contact force and bonding strength of joints. The contact force played an important role (Ors and Keskin 2008; Hu et al. 2018). In order to get the most direct experimental results and reduce the uncertainty of the research, the mortise and tenon joints were not glued in the experimental research. Therefore, the effect of mortise and tenon contact force on the structure was only studied.

In general, most previous studies on furniture structure have taken the T-shaped and L-shaped joints as basic components, focusing on joint strength and failure mode (Li 2006; Derikvand and Ebrahimi 2014), but the overall mechanical properties of the cabinet in practical application were not taken into consideration. However, the above studies on the mechanical properties of dovetails provided a lot of reliable reference values for the research of the present paper.

Miter spline is the most common connector in modern furniture structure. It is mainly used for the right-angle joint of planes, which plays a role in reinforcement and positioning in furniture (Jensen et al. 2001). The contact force of the miter spline mainly depends on the friction force generated by the interference fit (Hu et al. 2018), and the contact force of the dovetail in addition to the above two forces also includes the joint force generated by the joint squeezing force (Li and Yang 2011). In the same state, the contact force of the miter spline is much lower than the dovetail. Considering that the miter spline is easy to install and low in cost, if a squeezing force can be generated, its joint contact force can be further improved.

By improving the design of the two types of tenon and mortise structure, a new dovetail key has appeared (Wang and Chen 2016), which combines the advantages of dovetail and miter spline. The characteristic of the box connected by this kind of joint is that it can produce a certain degree of squeezing force in addition to the frictional force at the nodes, and each node of the box has the same ability to resist external forces. Through compressive experiments and tensile experiments, the effects of different tenon and mortise sizes on its structural performance was studied.

\section{EXPERIMENTAL}

\section{Material}

The material of the specimen was poplar wood modified by melamine resin (MF modified poplar wood). The wood was provided by Jiangsu Linyang Wood Technology

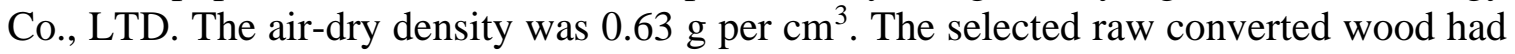
no scars or defects. The width was no less than $200 \mathrm{~mm}$.

The method of impregnation and modification of poplar is as follows:

a. Using melamine, urea and formaldehyde as the main raw materials, and sodium 
hydroxide as the catalyst, synthesize melamine resin under the conditions of $80{ }^{\circ} \mathrm{C}-90^{\circ} \mathrm{C}$ (main performance index: viscosity $26.5 \mathrm{mPa} . \mathrm{s}$, solid content $52.3 \%$, water mixing multiple is greater than $8, \mathrm{pH} 10.2$ ), stored for 30 days.

b. Dilute with water to a $25 \%$ mass concentration solution for future use.

c. Place the test material in an airtight treatment tank, first evacuate to $-0.095 \mathrm{MPa}$ and hold for $45 \mathrm{~min}$.

d. Inject the treatment liquid into the treatment tank. After releasing the vacuum, apply a pressure of $0.8 \mathrm{MPa}$ to the tank, and release the pressure after 2 hours.

e. Air-dry the modified material to a moisture content of less than $30 \%$, then put it in an oven to dry, and finally obtain a modified treated material with a moisture content of about $10 \%$.

\section{Description of Specimens}

All of the specimens were processed using a computerized numerical control machine with an accuracy of $0.01 \mathrm{~mm}$ (WPC, YuLi, China). Figure 1 shows the detailed structure of the specimen. First, the specimen was cut into 4 plates of the same size after the end had been removed (the included angle of the section surface was $45^{\circ}$ ). Three equally spaced grooves were then processed along the bevel by using a dovetail mortise milling cutter (bevel angle $76^{\circ}$ ). The dovetail splines were then inserted into the grooves and then pressed to make the surrounding sealing box. Finally, the combined surface was polished with sandpaper until it was flat with the outer surface. As shown in Fig. 2, the grain orientations of the width direction of the plate and the dovetail key were defined as the tangential direction, and the tangential directions were perpendicular to them.

The appearance of the specimen was square, and the size was $250 \mathrm{~mm}$ by $250 \mathrm{~mm}$ by $100 \mathrm{~mm}$. Additionally, the thickness of the plate was $14 \mathrm{~mm}$, the interference volume was $0.1 \mathrm{~mm}$, and the ratio of the hole depth $(D)$ to the height of the inclined plane $(H)$ was $T(T=D \div H)$. The values of $T$ were as follows: $T_{1}$ was $50 \%, T_{2}$ was $75 \%$, and $T_{3}$ was $100 \%$. The depth of the groove is shown in Fig. 3. Before the test, all specimens were stored in a constant temperature and humidity environment to ensure that their moisture content was approximately 10\%. The size of the dovetail keys is shown in Fig. 4.

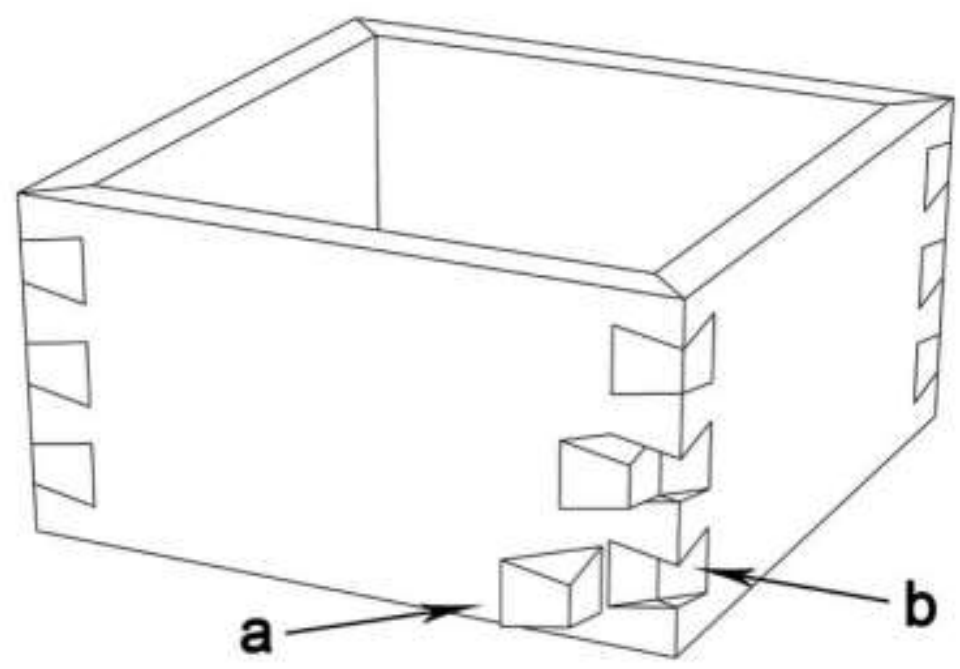

Fig. 1. Box connected by dovetail keys. (a) Dovetail key; (b) groove 


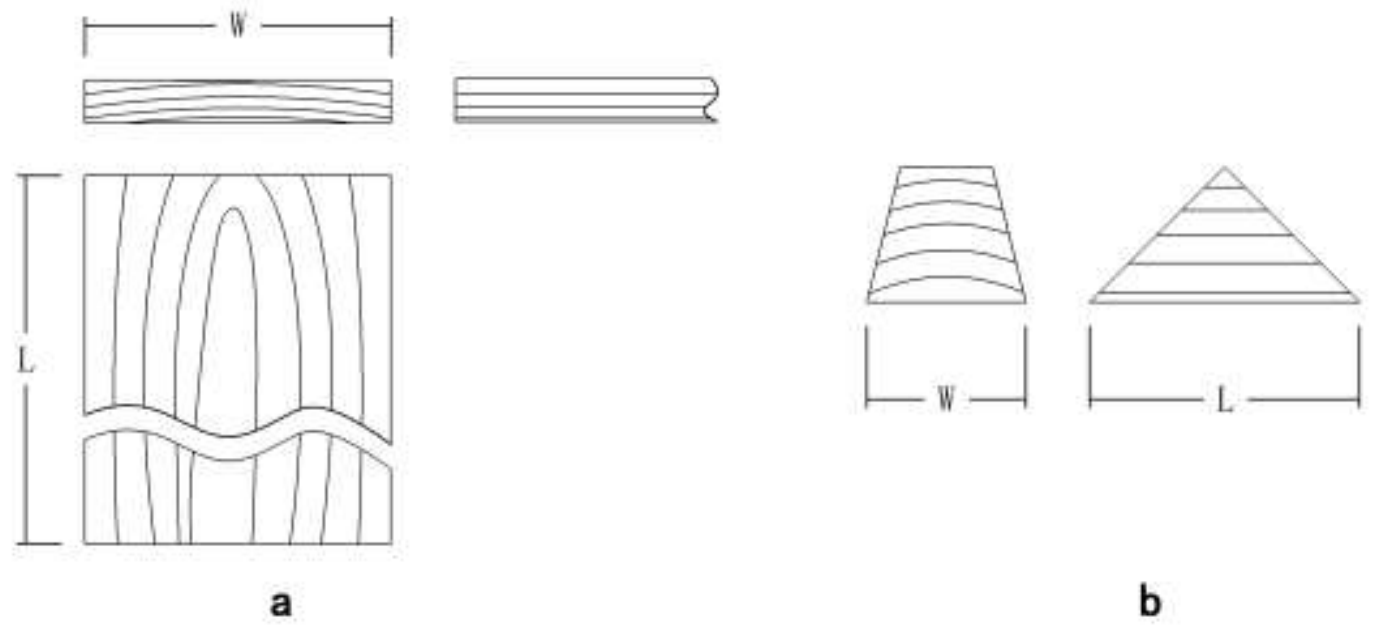

Fig. 2. Grain orientations (i.e., the plate is Fig. 1-a, the dovetail key is Fig. 1-b)

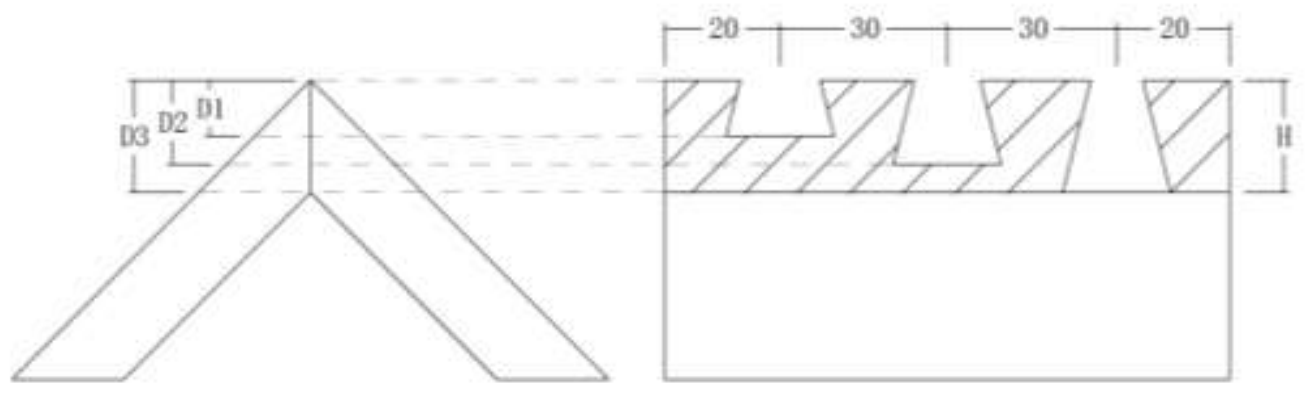

Fig. 3. Size of grooves, shown in $\mathrm{mm}$

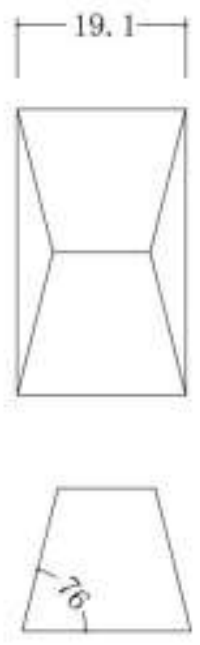

a
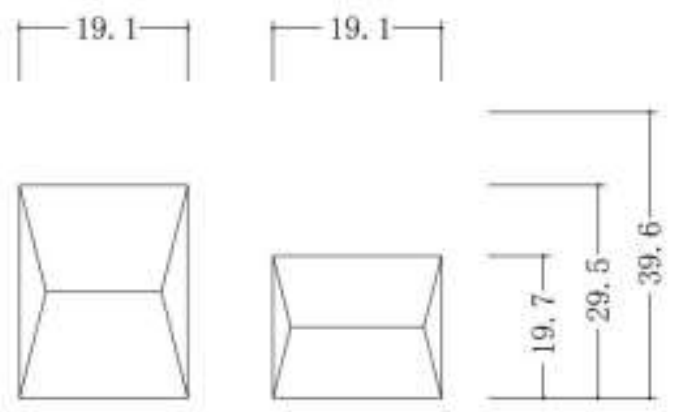

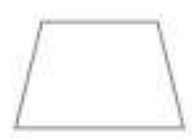

b

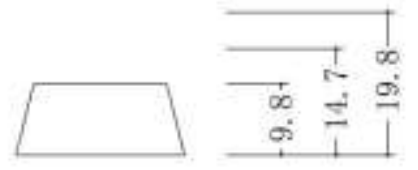

C

Fig. 4. Size of the dovetail keys for $T_{3}(\mathrm{a}), T_{2}$ (b), and $T_{1}$ (c), shown in $\mathrm{mm}$ 


\section{Testing Methods}

A $20 \mathrm{kN}$ universal testing machine (AGS-X, Shimadzu, Kyoto, Japan) and a constant temperature and humidity box (DHG-905385-Ш, Xinmiao, ShangHai) were used. The fixture used in the tensile test adopted the steel mold designed by the authors. The detailed dimensions of the mold are shown in Fig. 5.

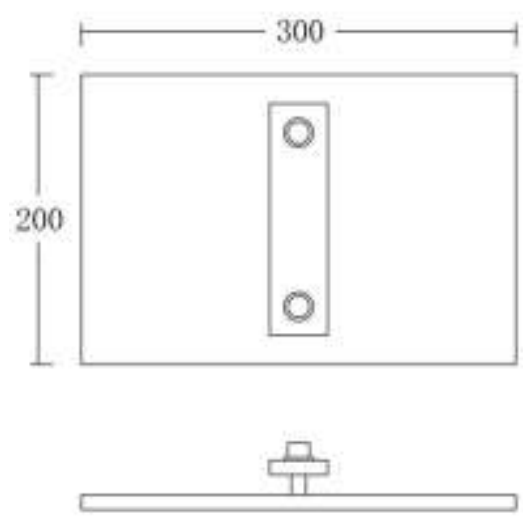

a
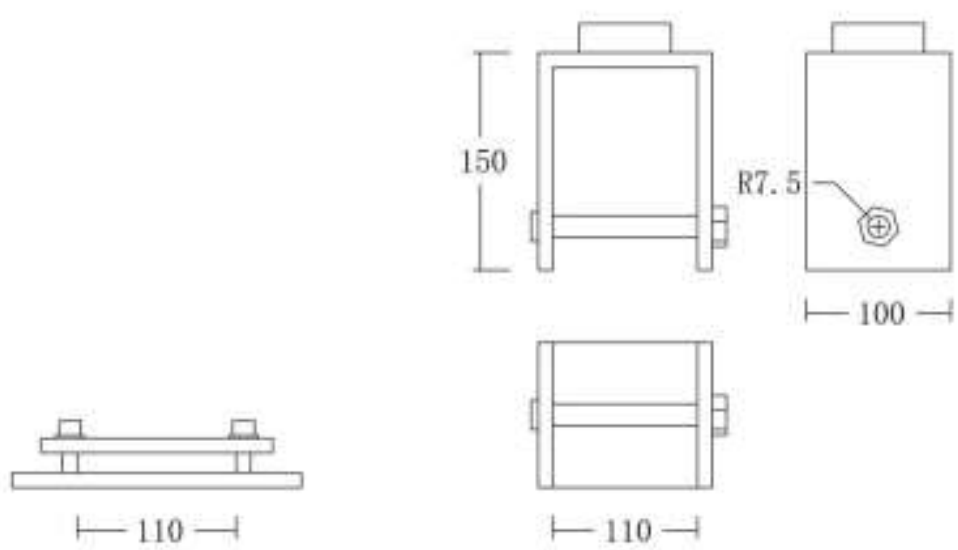

b

Fig. 5. Dimensions of the fixing device (a) and the stretching device (b), shown in $\mathrm{mm}$

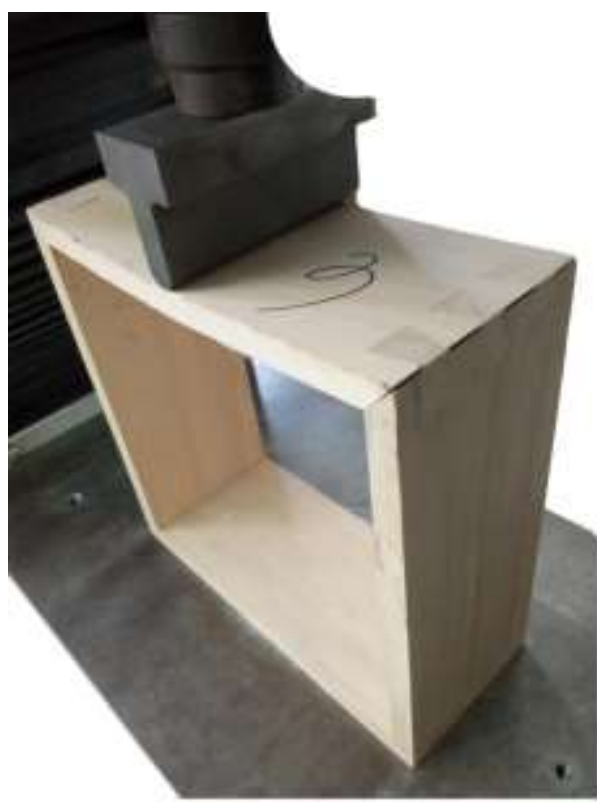

a

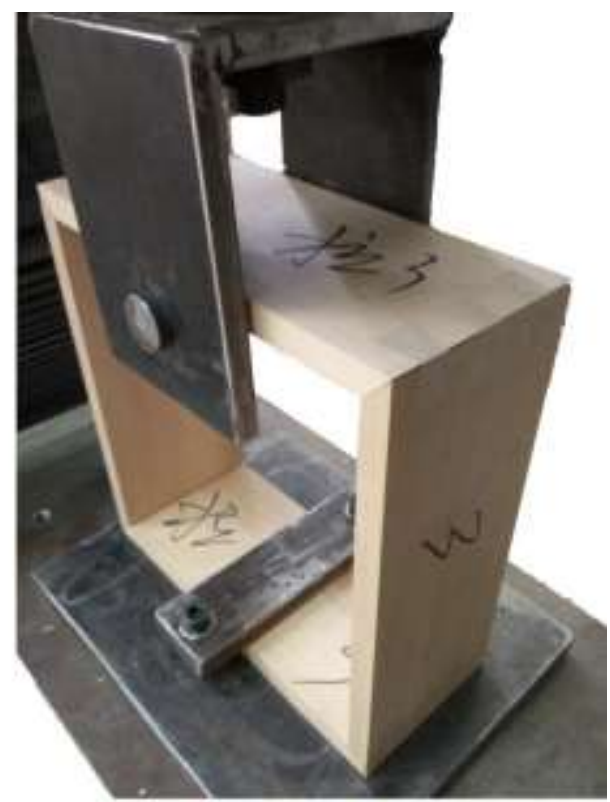

b

Fig. 6. Test methods for compression (a) and tensile (b)

This experimental method was proposed based on GB/T 10357.4 (1989). Since the dovetail key relies on the interactive contact force generated by the four nodes in the box to achieve the self-locking effect, the entire box as the experimental object can fully reflect the mechanical properties of the dovetail key. This experiment only tested the mechanical properties of the box under a concentrated static load, so the stress was mainly concentrated 
on the upper end of the box. The experimental loading mode is shown in Fig. 6, where $P$ is the loading force, and the stress line is in the middle of the board at the upper end of the specimen (125 mm away from the end of the joint). The loading force $P$ was vertically and uniformly loaded, and the speed was set at $10 \mathrm{~mm}$ per s. To obtain the ideal experimental effect, it was necessary to exclude the interference of wood fracture on the experimental results. Therefore, before the experiment, pre-experiments were required for each group of specimens to obtain the displacement interval before the wood fracture. By determining the most appropriate value of displacement, the formal experiments were carried out. The specimens at three levels of the compressive test were measured 9 times among 3 preexperiments and 6 formal experiments. The total sample quantity was 54. The quantity measured in the compression experiment was the same in the compression experiment.

\section{RESULTS AND DISCUSSION}

\section{Analysis of the Pre-experiment Result and the Value of Displacement}

According to the two different measurement methods, the basis for determining the displacement was different. The compressive test was measured under the condition of a fractured upper plate. The minimum displacement at three levels should be taken as the reference value (approximately $8 \mathrm{~mm}$ ). However, the tensile test was measured under the condition where the spline at the joint produced no displacement, which should be based on the minimum displacement of an optimal level. The results of the pre-experiments are shown in Table 1. The displacement reference value of the compression test was approximately $8 \mathrm{~mm}$, while the tensile test was approximately $5 \mathrm{~mm}$. Formal experimental measurements were made according to the obtained reference values.

Table 1. Load Relative Displacement

\begin{tabular}{|c|c|c|c|c|c|c|}
\hline \multirow{2}{*}{ Level } & \multicolumn{6}{|c|}{ Displacement $(\mathrm{mm})$} \\
\cline { 2 - 7 } & \multicolumn{5}{|c|}{ Compressive Test } & \multicolumn{3}{c|}{ Tensile Test } \\
\hline $\mathrm{T}_{1}$ & 8.55 & 9.33 & 9.66 & 4.54 & 2.58 & 3.31 \\
\hline $\mathrm{T}_{2}$ & 8.02 & 9.28 & 8.87 & 5.05 & 6.41 & 6.56 \\
\hline $\mathrm{T}_{3}$ & 8.36 & 8.84 & 8.67 & 3.91 & 4.72 & 4.16 \\
\hline
\end{tabular}

\section{The Effects of Mortise and Tenon Size on the Compressive Performance of Joints}

The compressive behavior of the box at different levels is shown in Fig. 7. The whole compression process mainly included plastic deformation, elastic deformation, and elastic-plastic deformation. The load-displacement curve at a certain level includes the $o$ $a$ stage where there was mainly plastic deformation. At this time under the loading of external forces, all four joints of the specimen were squeezed. This gradually reduced the seam error caused by assemblage. When the error disappeared, the plastic deformation ended. From point $a$, the specimen underwent elastic deformation due to the resistance to external forces. The $a-b$ stage conformed to Hooke's law. Within this range, the load and displacement had a linear relationship. When the external force was greater than its static friction force of the joint, the spline produced displacement and plastic deformation occurred. However, at this time the yield limit of the wooden board had not been reached, and elastic deformation still existed. This means that there was elastic-plastic deformation at the $b$ - $c$ stage. In addition, the relationship between load and displacement at different 
levels was fitted by Origin software. As shown in the fitting equation, the correlation coefficients of 1,2 , and 3 were all over 0.99 .

$$
\begin{array}{ll}
F\left(T_{1}\right)=0.5607 \mathrm{x}+0.0919 \mathrm{x}^{2}-0.0104 \mathrm{x}^{3} & R^{2}=0.99636 \\
F\left(T_{2}\right)=0.6995 \mathrm{x}+0.0904 \mathrm{x}^{2}-0.0109 \mathrm{x}^{3} & R^{2}=0.99785 \\
F\left(T_{3}\right)=0.5406 \mathrm{x}+0.1048 \mathrm{x}^{2}-0.0113 \mathrm{x}^{3} & R^{2}=0.99208
\end{array}
$$

where $F$ represents the load $(\mathrm{kN}), T_{1}, T_{2}$, and $T_{3}$ represent the different levels, and $R^{2}$ represents goodness of fit. As shown from the fitted curve in Fig. 6, the increase of the displacement resulted in the tested specimens of level $T_{2}$ having a better resistance than level $T_{1}$ and $T_{3}$.

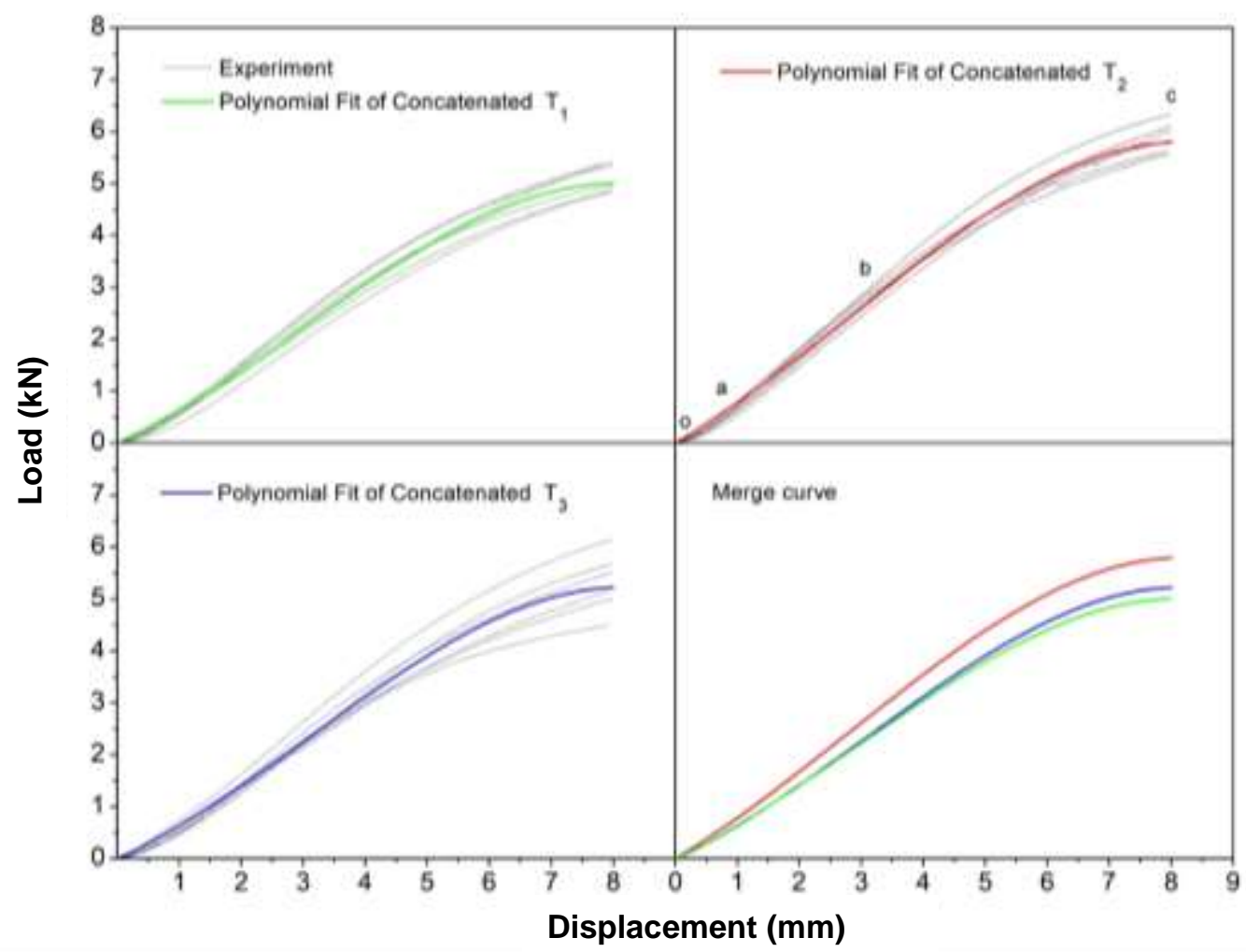

Fig. 7. The compressive behavior of the box at different levels

According to Table 2 at level $T_{2}$, the mean tensile load of the specimens was 5.921 $\mathrm{KN}$ at most, which was $11 \%$ higher than level $T_{3}$ and $15 \%$ higher than level $T_{1}$.

As can be seen from Table 3, the significant difference $F=6.04$, and the corresponding test level $\mathrm{P}=0.0119$. According to the value range of test level $\mathrm{P}$, that is, 0.01 $<\mathrm{P}<0.025$, it can be concluded that the value of $T$ has a significant effect on the compressive load value of the specimen.

Table 2. The Maximum Compressive Load of the Specimen

\begin{tabular}{|c|c|c|c|c|c|c|c|}
\hline Level & \multicolumn{5}{|c|}{ Load $(\mathrm{kN})$} & Average \\
\hline$T_{1}$ & 4.863 & 4.969 & 5.344 & 5.388 & 4.859 & 5.428 & 5.142 \\
\hline$T_{2}$ & 6.103 & 5.591 & 5.619 & 6.338 & 5.838 & 6.034 & 5.921 \\
\hline$T_{3}$ & 5.525 & 6.152 & 5.675 & 5.016 & 5.138 & 4.503 & 5.335 \\
\hline
\end{tabular}


Table 3. Variance Analysis of the Maximum Compressive Load

\begin{tabular}{|c|c|c|c|c|c|}
\hline Source & Sum of Squares & df & Mean Square & F & Sig. \\
\hline Between Groups & 1.9731524 & 2 & 0.98657622 & & \multirow{2}{*}{6.04} \\
\cline { 1 - 4 } Within Groups & 2.4497312 & 15 & 0.16331541 & & \\
\cline { 1 - 4 } Total & 4.4228836 & 17 & 0.26016962 & & \\
\hline
\end{tabular}

The degree of compressive failure of the joints at different levels is shown in Fig. 8. The restoring force of the structure has a remarkable influence on the damage degree of the contact surface. After the load disappeared, the spline of the specimen at the $T_{1}$ level broke, leading to the weak joint restoring force. The most serious damage done occurred on the contact surface. However, due to the small amount of spline slip at the $T_{2}$ and $T_{3}$ level, the box structure could overcome its own frictional force and return to the original state. The structure overcame its friction as much as possible after the fixture was removed. The recovery effect of the joints was better at the $T_{3}$ level, followed by level $T_{2}$, and was worst at level $T_{1}$.
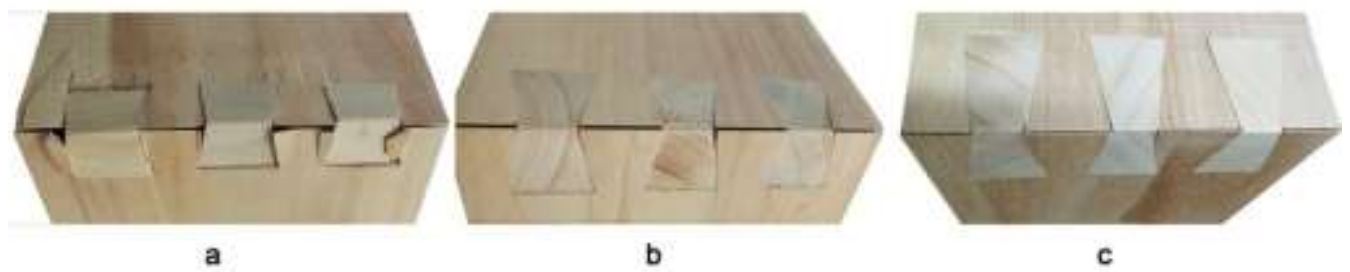

Fig. 8. Compressive failure (i.e., $T_{1}$ is Fig $7-a, T_{2}$ is Fig 7-b, and $T_{3}$ is Fig 7-c)

\section{Effect of Mortise and Tenon Size Ratio on the Tensile Performance of Joints}

The tensile behavior of the box at different levels is shown in Fig. 9. According to the measurement standard of tensile tests, the whole stretching process mainly went through the elastic deformation stage before a remarkable displacement of the joint was produced. The measurement standard of the tensile test is that the joint does not shift during the experiment, so the deformation of the joint at this stage is elastic deformation, not plastic deformation that produces deformation. But according to the final experimental results, the displacements of the joints at the $T_{1}$ and $T_{3}$ level were different. The joint force of the four joints was unstable at level $T_{1}$, resulting in a large dispersion of the curve. At level $T_{3}$, the contact force was relatively stable within the range of $0 \mathrm{~mm}$ to $4 \mathrm{~mm}$. However, when the compression amount exceeded $4 \mathrm{~mm}$, the displacement of the joint generally occurred. Level $T_{2}$ showed no remarkable displacement behavior. By fitting the relationship between load and displacement at different levels with Origin, the corresponding fitting equations were obtained according to Eq. 4, 5, and 6,

$$
\begin{array}{ll}
F\left(T_{1}\right)=0.182 \mathrm{x} & R^{2}=0.94924 \\
F\left(T_{2}\right)=0.2758 \mathrm{x} & R^{2}=0.99597 \\
F\left(T_{3}\right)=0.2505 \mathrm{x} & R^{2}=0.98941
\end{array}
$$

where $F$ represents the load $(\mathrm{kN}), T_{1}, T_{2}$, and $T_{3}$ represent the different levels, and $\mathrm{R}^{2}$ represents goodness of fit.

Their correlation coefficients all exceeded 0.94. This indicated that the curve had a high goodness of fit and could be used for model analysis. There was a linear relationship between the load and the displacement. Moreover, with the increase of displacement, the specimens at level $T_{2}$ had superior tensile resistance compared to level $T_{1}$ and $T_{3}$. 


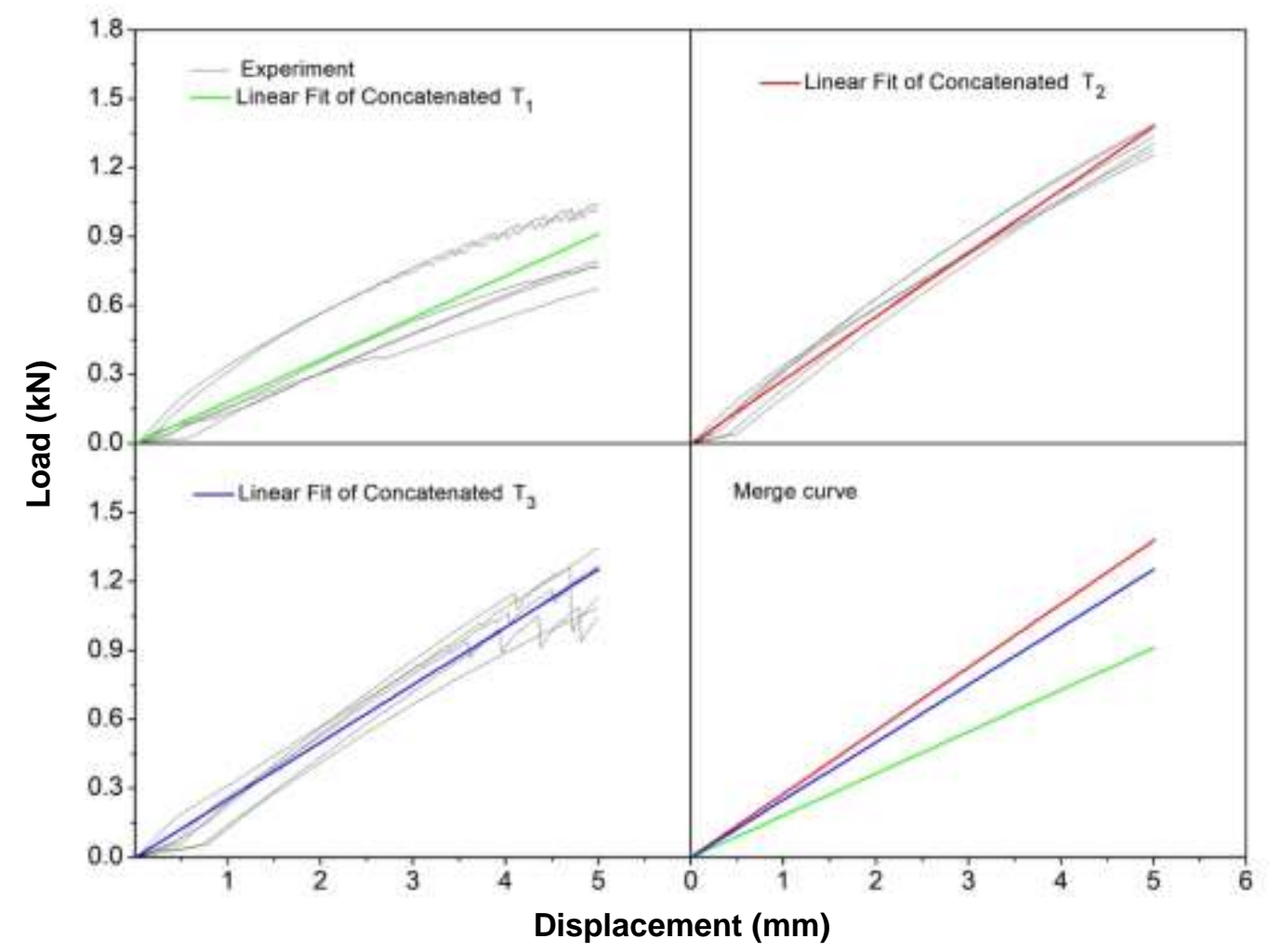

Fig. 9. The tensile behavior of the box at different levels

The joints at level $T_{1}$ and $T_{3}$ had different degrees of displacement. To unify the evaluation standard, the value of the load generated by stretching to $5 \mathrm{~mm}$ was used as a measurement index in this experiment. As shown in Table 4, the average tensile load at level $T_{2}$ was the largest at $1.327 \mathrm{KN}$, which was $11.4 \%$ higher than level $T_{3}$ and $56.7 \%$ higher than level $T_{1}$.

As can be seen from Table 5, the significance difference $F=27.71$, and the corresponding test level $\mathrm{P}=0$. According to the value of the test level $\mathrm{P}$, it can be concluded that the value of $T$ has a very significant effect on the tensile load value of the specimen.

Table 4. The Tensile Load of Specimens

\begin{tabular}{|c|c|c|c|c|c|c|c|}
\hline Level & \multicolumn{6}{|c|}{ Load $(\mathrm{kN})$} & Average \\
\hline$T_{1}$ & 1.029 & 0.769 & 1.042 & 0.796 & 0.774 & 0.674 & 0.847 \\
\hline$T_{2}$ & 1.385 & 1.391 & 1.256 & 1.338 & 1.308 & 1.282 & 1.327 \\
\hline$T_{3}$ & 1.266 & 1.046 & 1.138 & 1.270 & 1.338 & 1.087 & 1.191 \\
\hline
\end{tabular}

Table 5. Variance Analysis of the Maximum Tensile Load

\begin{tabular}{|c|c|c|c|c|c|}
\hline Source & Sum of Squares & df & Mean Square & $\mathrm{F}$ & $\mathrm{P}$ \\
\hline Between Groups & 0.73240678 & 2 & 0.36620339 & \multirow{3}{*}{27.71} & \multirow{3}{*}{0} \\
\hline Within Groups & 0.1982235 & 15 & 0.0132149 & & \\
\hline Total & 0.93063028 & 17 & 0.05474296 & & \\
\hline
\end{tabular}


As shown in Fig. 10, the joints of level $T_{1}$ and $T_{3}$ were damaged to varying degrees when compared to level $T_{2}$. The tensile strength of the joint depended on the friction force of the mortise and tenon joint. Due to the roughness of the contact surface, the frictional force generated by each joint was slightly different. At the early stage of loading, the static friction force was greater than the external force and no obvious deviation occurred on each contact surface. At the later stage of loading, when the external force was greater than the static friction force, the contact surface began to shift where the friction was low resulting in joint failure.

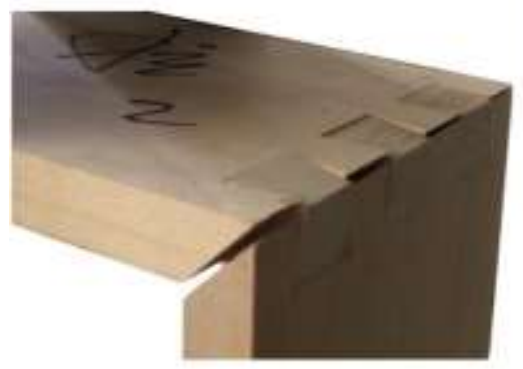

a

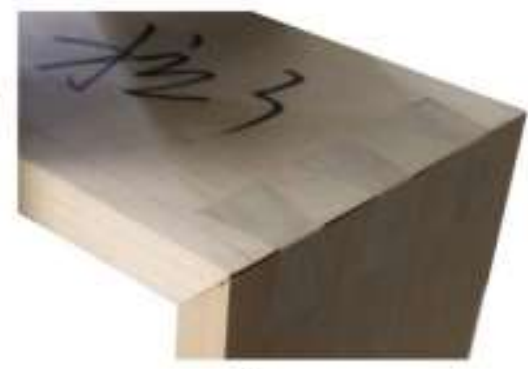

b

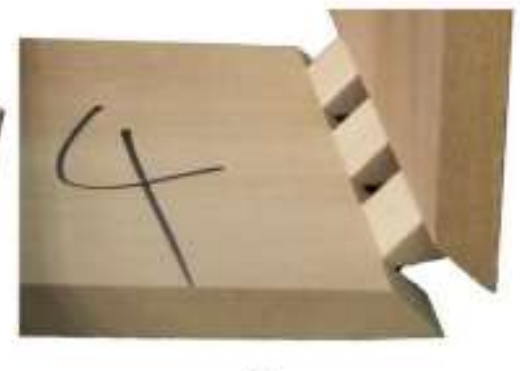

c

Fig. 10. Tensile failure (i.e., $T_{1}$ is Fig $9-a, T_{2}$ is Fig $9-b$, and $T_{3}$ is Fig 9-c)

\section{CONCLUSIONS}

1. In this paper, by referring to the results of the pre-experiment, the reliable measurement standard was improved for the formal experiment. The results showed that under the conditions of compression of $8 \mathrm{~mm}$ and stretching of $5 \mathrm{~mm}$, the joint strength of the box was as follows: level $T_{2}$ was greater than level $T_{3}$ and level $T_{3}$ was greater than level $T_{1}$.

2. At level $T_{2}$, the compressive strength of the joint was $11 \%$ higher than level $T_{3}$ and $15 \%$ higher than level $T_{1}$. Additionally, the tensile strength was $11.4 \%$ higher than level $T_{3}$ and $56.7 \%$ higher than level $T_{l}$.

3. At level $T_{2}$, the box structure had a remarkable advantage in tensile property.

4. The size of the dovetail key had a significant effect on the compression and tensile properties of the box, especially in the tensile properties.

\section{ACKNOWLEDGMENTS}

This study was supported in part by the University-Level Research Fund of the Nanjing Institute of Technology (Grant No: QKJ201806), in part by the Special Fund for Forest Scientific Research in the Public Welfare (Grant No: 201404501), and in part by the Major Subject of the Education Department of Jiangsu Province (Grant No: 2018SJZDA015). 


\section{REFERENCES CITED}

Derikvand, M., and Ebrahimi, G. (2014). "Finite element analysis of stress and strain distributions in mortise and loose tenon furniture joints," Journal of Forestry Research 677-681. DOI:10.1007/s11676-014-0507-5.

GB/T10357.4 (1989). "Test of mechanical properties of furniture. Stability of storage units," Standardization Administration of China, Beijing, China.

Hu, W. G., Wan, H. and Guan, H. Y. (2018). "Study on contact force relaxation behavior of mortise-and-tenon joints considering tenon fits and grain orientations of tenon," Bioresources 13(3), 5608-5616. DOI: 10.15376/biores.13.3.5608-5616

Jensen, J. L., Koizumi, A., Sasaki, T., Tamura, Y., and Iijima, Y. (2001). “Axially loaded glued-in hardwood dowels," Wood Science and Technology 35(2), 73-83. DOI:10.1007/s002260000076.

Li, X. J., and Yang, Y. F. (2011). "Study on joint strength of paulownia furniture based on connectionless quick disassembly structure," China Wood-Based Panels 7-10. DOI: CNKI:SUN:CWBP.0.2011-10-002.

Li, X. S. (2006). "Research on joint strength of frame joints of pine furniture," Ph.D. dissertation, Forestry and Technology Univ., Changsha., China.

Ors, Y., and Keskin, H., (2008). Wood Material Technology, Textbook, Gazi University Publication No: 2000/352, Gazi publishing, Ankara, Turkey.

Wang, L., Wang, Z., Zhou, X. W., Xiang, Q., and Zhao, R. J. (2015). "Connection mode and performance of wood structure joint," China Forest Products Industry 42(12), 48-51. DOI:10.19531/j.issn1001-5299.2015.12.015.

Wang, Q. Y., and Chen, Y. S. (2016). "Analysis of structural parts and nodes of modern solid wood chair furniture," Furniture 37(1), 19-23. DOI:10.16610/j.cnki.jiaju.2016.01.004.

Wang, S. (2016). “A box with a dovetail joint," by Patent CN205064471U [Online]. Available: cnki.net: SCPD2016: CN105134700A.

Yang, J. F. (2017). Effect of Parameters on Mechanical Properties of Mortise and Tenon Structures, Master's Thesis, Beijing University of Technology, Beijing, China.

Zhang, S., Yang, J. F., and Long, L. C. (2019). "Analysis on tensile strength of dovetail tenon," in: The $25^{\text {th }}$ Academic Annual Meeting of Beijing Mechanics Institute, Beijing, pp. 684-685.

Article submitted: March 17, 2020; Peer review completed: May 24, 2020; Revised version received and accepted: June 3, 2020; Published: June 5, 2020.

DOI: $10.15376 /$ biores. 15.3.5776-5786 